\title{
Managing Value Creation in Knowledge Intensive Business Services Organisations
}

\author{
An Organisational Design Based on Viable System Model
}

\author{
Yu-Chun Pan \\ Business School, Oxford Brookes University, Oxford, UK \\ ypan@brookes.ac.uk
}

\author{
Paul Jackson \\ Business School, Oxford Brookes University, Oxford, UK \\ pjackson@brookes.ac.uk
}

\author{
Diana Limburg \\ Business School, Oxford Brookes University, Oxford, UK \\ dlimburg@brookes.ac.uk
}

\begin{abstract}
Value creation is essential in the Knowledge Intensive Business Service (KIBS) industry, due to its problemsolving nature. KIBS organisations need to understand their internal value creation processes as well as the complexity in the environment in order to survive and thrive. This paper investigates how value creation is managed in KIBS organisation through a case study. It then goes on to adopt Beer's Viable System Model (VSM) to propose an organisational design, namely the Value Integration Office (VIO). The VIO focuses on the 5 functions/systems defined by VSM in the meta-system and operation of an organisation in order to manage value creation. This design is implemented in a case study organisation with the aim to adopt a holistic view on value creation within the organisation as well as facilitate future planning function. The implementation and impact of the proposed organisational design are reported in this paper.
\end{abstract}

Keywords-Organisational Design; Legal Profession; Value Creation; Knowledge Intensive Business Service; Service Management

\section{INTRODUCTION}

Knowledge intensive business services (KIBS) organisations accumulate, create and disseminate supplier's specialist knowledge to deliver customised services or solutions to satisfy customer needs [1, 2]. In recent years, legal services, as a type of KIBS, have been under pressure to improve their process efficiency to meet modern world customers' requirements at a lower cost via adopting the techniques and technologies already widely used in other industries $[3,4,5,6,7]$. In the UK, since the recession and the advent of the Legal Service Act 2007, non-lawyers have been allowed to enter the legal market, which consequently has increased the level of competition [8]. Legal practitioners face difficult challenges in adapting their organisational structures,

This project received financial support from the Knowledge Transfer Partnership (KTP). KTP is funded by Innovate UK along with other government funding organisations. work processes and cost models [8, 9].

Value creation literature has focused on the process logics $[10,11]$, the exchange of information [12] and the interactive process between service providers and customers [13]. However, there is little literature on the organisational structure of KIBS firms from a holistic perspective. This paper reviews the literature on value creation processes, particularly in KIBS, in order to understand the how value is created and managed. Then through a case study in the legal industry, this paper examines the reasons behind the difficulties that KIBS organisations face in managing value creation processes in the changing environment. Beer's Viable System Model [14] is then used to examine how organisational design can be used to support value creation processes in a dynamic environment. Based on VSM, this paper aims to propose an organisational structure that enables organisations in the KIBS to continuously adapt to create value in a dynamic marketplace.

\section{THEORETICAL BACKGROUND}

\section{A. Value Creation}

The creation of value is the main purpose of business operations. It consists of a process that requires resources and activities to deliver benefits to customers. Porter [15] introduced the concept of value chain, which views the primary value-adding process as a sequence of activities. Stabell and Fjeldstad [16] argued that Porter's value chain analysis does not describe the value-adding activities in nonmanufacturing industry, and propose additional value configurations, including 'value shop' and 'value network'. The value chain, shop and network logic have been the genesis of many studies on value creation. Johansson and Jonsson [10] investigate the chain and shop logics and further propose the 'package logic'. This 'package logic' recognises that generic problems exist in business situations for which organisations 
can provide packaged 'underlying solutions' to the problem owners. Such solutions, say the authors, can be customised and utilised across projects and customers, providing for greater efficiency and economies of scale. The shop and package logics, where value creation occurs through a problem-solving process, appear in many areas, including high-tech product development [17], professional services and KIBS $[2,18,19]$.

The problem-solving nature of KIBS significantly shapes how value is created in KIBS organisations. The problems to be solved may not be clearly structured and therefore rely on the specialist knowledge to clarity the problems [20]. Professional knowledge and competence are therefore key elements of value creation [21]. In addition to the specialist knowledge, the roles in diagnosing needs, designing and producing solutions, organising process and resources and implementing solutions are vital in the value creation process in KIBS [22].

\section{B. Viable System Model}

An organisation can be seen as a system with defined boundary composed of inputs, processes and outputs, and contains distinctive parts that are integrated to accomplish a shared goal [23]. Such a system view enables the management to regard the organisation in terms of the flows, processes and relationships, to achieve optimal results [24]. The system view of organisation also allows each system to be analysed in relation to its meta-systems and sub-systems. In addition to investigating the elements within a system, Beer [25] stated that it is necessary to observe a system from a higher level, with a holistic perspective, to fully address the phenomenon. By viewing organisations as systems, a holistic view enables the investigation into the full scenario of functioning organisations, including how they interact with environments.

Beer [14] applied Ashby's Law of Requisite Variety [26] to develop the concept of Viable System Model (VSM). VSM [14] sees an organisation as a system that becomes viable by balancing internal and external factors. The internal resources must match the variety of the external requirements. VSM provides a framework for reviewing and designing responsive and sustainable organisations that match internal variety and external complexity [27]. VSM was originated from cybernetics and developed largely based on the idea of complexity in the environment. VSM describes how an organisation as an autonomous system meets the complex demands to survive and be viable in the changing environment. VSM has been widely adopted to understand and design organisational structures and information systems in various fields, such as complex systems and communications systems [28, 29, 30].

The three key elements in VSM are operation, environment and meta-system. The meta-system enables and ensures that operational units work in harmony, by providing control and guidance, while both the meta-system and operation interact with the environment and exchange information. The meta-system and operation together form a viable system. Each viable system is composed of five systems that have specific roles and functions within an organisation (see TABLE I. and Fig. 1). VSM holds that an organisation can achieve its viability by the coherent collaboration of the five systems.

TABLE I. Five Systems of Viable System Model [14]

\begin{tabular}{|l|l|l|}
\hline Element & System & \multicolumn{1}{|c|}{ Descriptions } \\
\hline Operation & System 1 & $\begin{array}{l}\text { The collection of operational units that perform } \\
\text { primary tasks }\end{array}$ \\
\hline \multirow{3}{*}{$\begin{array}{l}\text { Meta- } \\
\text { system }\end{array}$} & System 2 & $\begin{array}{l}\text { The system responsible for the communication } \\
\text { between system 1 and 3 and between } \\
\text { operational units in system 1 }\end{array}$ \\
\cline { 2 - 3 } & System 4 & $\begin{array}{l}\text { The structure and control of operation, ensuring } \\
\text { integration of value; also provides an interface } \\
\text { with system 4 and 5 }\end{array}$ \\
\cline { 2 - 3 } & $\begin{array}{l}\text { The system that interacts with and investigates } \\
\text { the environment and develops future strategies } \\
\text { and plans }\end{array}$ \\
\hline System 5 & $\begin{array}{l}\text { The system that makes policy decisions, } \\
\text { controls the organisation as a whole, and } \\
\text { balances time and resources spent on planning } \\
\text { and development and those needed for } \\
\text { operational delivery }\end{array}$ \\
\hline
\end{tabular}

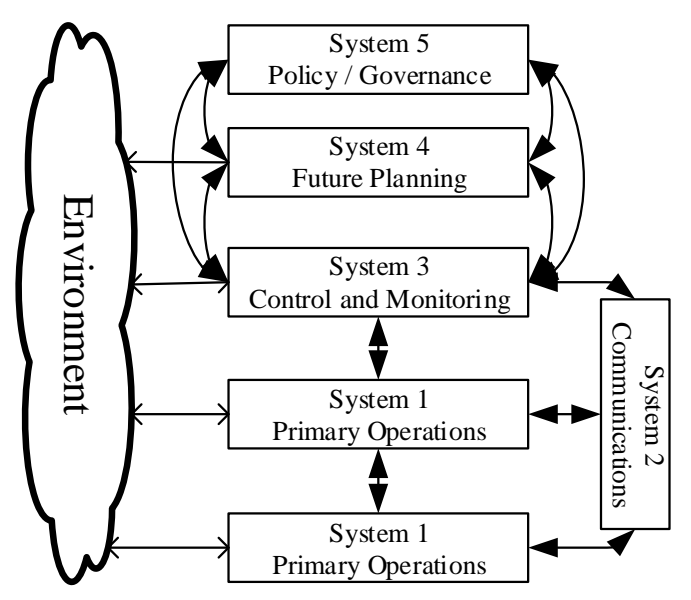

Fig. 1. Viable System Model [14]

One of the key foundations of VSM is that viable systems are recursive; viable systems contain viable systems. This allows organisations to understand the multiple layers of structures and functions, as well as their interactions with the environment.

\section{METHOD}

Through a case study, this paper provides empirical evidence of the difficulties in managing value creation processes in a KIBS context. The empirical study is primarily a qualitative case study based on participant observation [31]. A UK-based law firm was selected as the case study organisation. This organisation is of particular interest due to the knowledge-intensive nature of legal services and the level of change in the UK legal industry in recent years. The case study organisation offers a wide range of legal services to both business and individual customers. It has over 250 employees across 3 geographical locations. The rapid growth increases the level of complexity in business operations and in the 
marketplace, which challenges the management and organisational structure, designed prior to the growth. The first author started working with the case study organisation as an internal management consultant seconded from Oxford Brookes University in January 2014 and has been there for over a year. A large number of informal interviews were conducted with the employees at board, senior and junior levels. As such, the case study has benefited from the principle that data collected through observation in a natural setting can provide a more accurate insight into organisations [32].

The case study has three distinct phases. Firstly, from January 2014 until approximately July 2014, the 'as-is' situation was observed and analysed. Based on these initial findings, and the literature on value creation and VSM, an organisational design to support value creation in KIBS in dynamic environment was developed. Finally, the proposed design was implemented in the case study organisation in stages. The implication and impact of the implementation in the last 8 months will be analysed and reported, followed by the discussion and conclusion.

\section{INITIAL CASE STUDY FINDINGS}

The case study organisation is structured based on the areas of legal expertise. There are 21 legal departments and 4 support function departments. Each department is managed by its head of department. All the heads of departments report to the executive board. The executive board is responsible for managing the day-to-day operations across the departments and for the overall governance of the organisation. The executive board meet every week to review the performance of all departments and make decisions on the operational plans for the departments. The executive board, as the only decision making and management function, spends the majority of the time ensuring the smooth daily operations, which leaves little time for long term planning. In terms of value creation, each department has, over the years, developed its own approach to value creation, based on interacting with the marketplace and its customers.

However, the knowledge flows about the practice of value creation within the organisation are mostly vertical, between the executive boards and each department. The lateral knowledge flows between legal departments are relatively limited. In brief, the case study organisation has a large number of value creation practices across the organisation, but there is no channel or mechanism for these value creation practices to be shared between departments. The departments therefore operate in silos and the executive board is the central hub that links all the departments.

From the VSM perspective, the departments are the primary operation units that interact with the environment and create value through daily operations (system 1). The reporting system (e.g. performance management system) between the heads of departments and the executive board represents the system 2 . The executive board controls and monitors the performance of all the departments (system 3). However, there is no system 2 functionality between the system 1 operational units. The executive board is also responsible for the overall governance (system 5) and future planning (system 4).

As seen in Fig. 2, whilst there are system 1, 2 and 3 in place, there is no clear distinction between system 3,4 and 5 in the meta-system. Furthermore, there is no distinction between system 3 local management and control and the strategic system 4 and 5. The fact that the executive board find it difficult to balance between daily operational management and long term strategic planning shows the shortfall of mixing system 3 and the meta-system. As a result, the functions of system 4 , which focuses on investigating the environment and future planning, are rarely performed. The lack of a system 2 function (coordination) between system 1 operational units (the legal departments) limits the case study organisation's ability to learn from experiences within the organisation and gain from the benefits of sharing best practice. The executive board currently performs the system 3 function, as well as the whole meta-system function. The lack of clear distinction and definition of the functions and responsibilities of system 3, 4 and 5 limits the case study organisation's ability to understand the environment and plan to adapt itself to the changes in the dynamic marketplace.

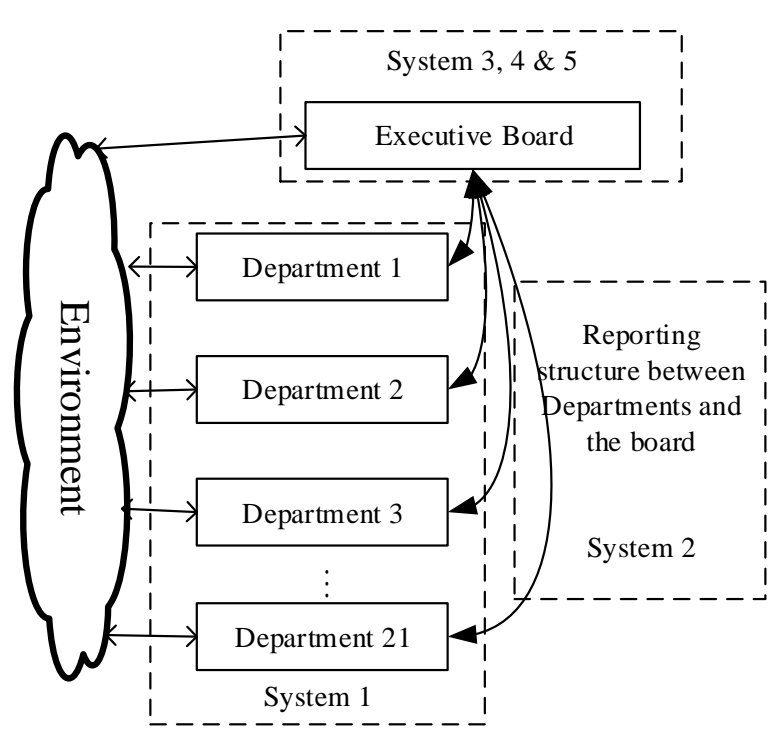

Fig. 2. Case Study Organisation from VSM Perspective

\section{VAlue INTEGRATION OFFICE}

Based on the initial case study findings, we identified that the current organisational structure, as well as the functions of the organisational units, did not fully support the long term growth and development of the organisation. Therefore, an organisational design based on VSM and the case study findings was developed. In order to address the imbalance in the meta-system, a Value Integration Office (VIO) was created to enable a holistic view of the organisation and required changes based on understanding the environment and internal resources. The VIO essentially fulfils the role of system 4 in VSM. The creation of the VIO is to release the governance body (system 5) from future planning responsibility, so that 
the governance body can focus on decision making on policy and governance issues. The governance body develops the corporate strategy with the support of the VIO. The main responsibilities of the VIO should include:

- Coordinate strategies and plans for improvement

- Develop and maintain a portfolio of change initiatives

- Facilitate knowledge exchange within the organisation

- Prioritise and coordinate projects and initiatives

- Curate business, technology and process architectures

- Support intelligence gathering (particularly from the marketplace) and organisational development

In order to perform the future planning function (system 4), the VIO gathers and analyses the information collected through the interaction between the departments (system 1 operational units) and from the environment. Based on the analysis, the VIO can initiate the change required in order to achieve the strategic goals set by the governance body (system 5 ). Once the changes are delivered and embedded into operations (via systems $1,2 \& 3$ ), the overall performance of the operational units can be reviewed by the governance body. The review can then form the foundation for the change initiatives.

In addition to the creation of the VIO, we also propose some structural change in operations in order to create the communications between operational units and the appropriate control function in the business operations. Fig. 3 shows a proposed structure, linking the VIO with newly created 'area managers'. The departments here are grouped into areas by customer portfolio and the nature of their work. The heads of departments report in turn to the area managers, who are responsible for managing the performances of the departments and collating the external environment information collected and reported by the departments. The area managers act as the middle-level management between the departments and the executive board. The area managers also initiate the lateral knowledge flow between the departments in the same area. In KIBS, this lateral knowledge flow can provide the essential foundation for the development of the bank of problemsolving practices, which are essentially the value creation processes. The awareness and understanding of the individual problem-solving instances enable the identification of the pattern of problem-solving practices. The knowledge about value creation then can be collated and analysed by the VIO, which ensures an organisation-wide knowledge management approach. The VIO thus processes the value creation knowledge pre-filtered by area managers and the information collected from the environment. The processed information is then provided to the executive board for strategic decision making and the area managers for operation management support.

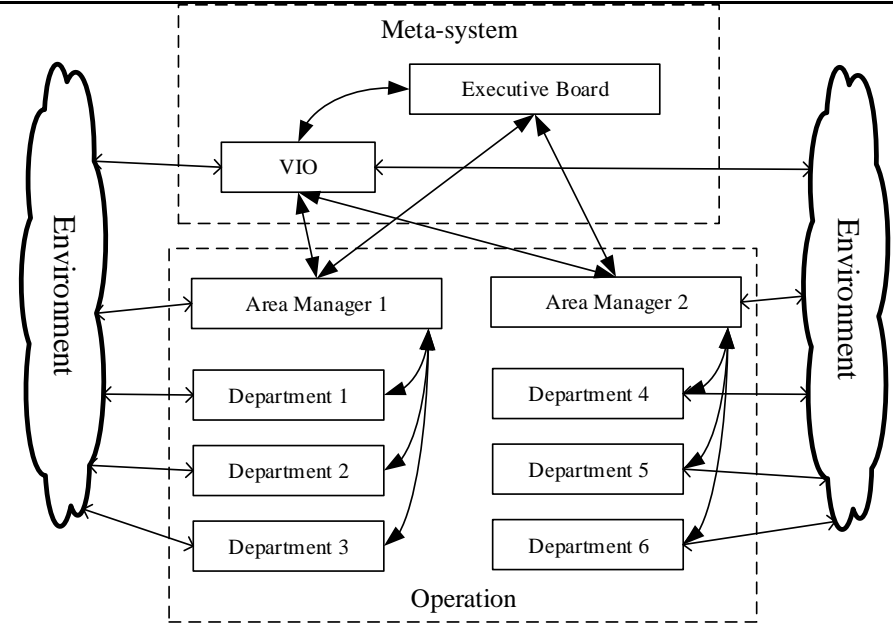

Fig. 3. Proposed Structure with VIO

The proposed structure aims to set clear roles and responsibilities of the operation and the meta-system. Within the meta-system, the executive board focuses on policy and corporate strategy (system 5 function), and the VIO focuses on future planning and change portfolio (system 4 function). The area managers are the hubs of the operation and are responsible for gathering information from operational units to feedback to the VIO and the executive board. The proposed structure and defined roles largely support the required functions identified by VSM for organisations to survive and grow in the environment.

\section{IMPLEMENTATION AND IMPACT OF VALUE INTEGRATION OFFICE}

Having been approved by the management team, the proposed organisational structure will be implemented in the case study organisation in stages, starting in July 2014. The implementation remains active at the time of writing this paper. The VIO was created first, in order to thoroughly review the current change initiatives in the organisation. This portfolio was then examined by the executive board and the VIO to terminate any initiatives without clear aims and objectives. Disciplines for all change initiatives have also been introduced to ensure the initiatives support the corporate strategy and only start when the required resources are secured. The defined procedure specifies the documents and information required to assess change initiatives. The introduction and implementation of the VIO required a number of workshops and public announcements in the organisation. Not only does the VIO play the role of a gatekeeper for the change initiatives, but it also provides support and guidance needed in the development of new change initiatives, thus acting as a 'Project Office'.

Once the VIO was up and running, the creation of area managers was initiated. The 21 legal departments were grouped into 6 areas based on the types of customers and the types of work the departments perform. For each area, an area manager was appointed based on the knowledge of the area and the management experience. A performance management 
system was introduced to support the area managers to monitor and control the performance in their areas and to report to the executive board. The unified performance management system provides the consistency and standard of communications between departments and between areas and the executive board.

Up to the point when this paper is written, the VIO has been operating for 8 months and the area managers have been in place for 3 months. It is therefore too early to review the impact of the structural change on the financial performance. However, the initial assessment of the new structure still provides valuable insight into the implementation of the VIO. The first author conducted unstructured interviews with the executive board and the area managers in order to understand the impact of the structural change and to collect feedback for further improvements. The executive board in general recognises the positive impact of the VIO in terms of ensuring the standard and consistency of new change initiatives. Under the new structure, the executive board focuses on future planning decisions with the VIO, and focuses on operational performance reviews with the area managers. The executive board find this approach helps them balance between managing the operations and planning for the future. The area managers are in the process of managing the departments in their areas. The performance management system is considered very helpful by the area managers and the executive board in terms of providing the same platform across the organisation. It allows the executive board to manage by exception rather than review all the details, which reduces the time demands on management. The area managers are also able to start facilitating the information sharing about customer knowledge and problem-solving approaches between the departments within their areas. Generally speaking, the executive board and the area managers see the implementation of the VIO and area managers as a positive contributor to the organisation, during the relatively short period of time since the structural change. However, the impact of change, particularly on the financial performance of the case study organisation, will still need to be monitored over time.

\section{DISCUSSION AND CONCLUSION}

The value creation process is the foundation of business operation. In the context of KIBS, value creation is even more important in the absence of physical goods. A service provided by KIBS organisations involves creating value through solving customers' problems. Due to the problemsolving nature of KIBS, knowledge exchange is central to value creation and integration within the organisation. Knowledge sharing about customers and problem-solving is the first step of ensuring the integration of value creation processes. Despite the different value creation logics, it is the specialist knowledge and the knowledge about customers and their problems that allow KIBS organisations to deliver value to their customers. It is therefore crucial that an organisation has knowledge about the environment, e.g. customers and market trends. This kind of knowledge allows organisations to adapt themselves in the environment, and thus to survive and thrive.
Beer's VSM [14] provides a framework that explains how an organisation can survive in the changing environment through performing a set of specific functions via the 5 systems. As the above discussion has shown, the structure and dynamics of the case study highlighted the difficulties of a KIBS organisation in terms of integrating its value creation processes and adapting itself in response to the changing environment. From the VSM perspective, the organisation did not have a clear distinction between monitoring, future planning and governance in terms of roles and responsibilities. The lack of clearly defined roles and responsibilities limited the organisation's ability to integrate its value creation processes and to adjust itself to suit the environment.

Because of this, an organisational design was proposed and implemented, consisting of a VIO and area managers, based on the concept of VSM. The proposed VIO enables the holistic view of the organisation by identifying and coordinating the information gathered and change initiatives proposed by different parts of the organisation. The VIO also filters out the unorganised and unsolicited information for the senior management. The central 'gatekeeper' role of the VIO allows an organisation to reduce the 'noise' from local management and focus on the strategic issues. Furthermore, the VIO acts as the portfolio office that enables an organisation to ensure all the change initiatives are in line with the organisation's long term strategies. The newly proposed area managers serve as the first level of cross-departmental collaboration within the areas, when the VIO facilitates the collaboration between the areas. This organisational structure allows the identified patterns of problems to be shared between different operational units. The shared patterns of problems and underlying solutions provide the foundation for package logics. Package logics of value creation are increasingly found in KIBS industry. An organisational design that focuses on the functions facilitating the development of coherent collaboration across the organisation would help organisations manage the value creation processes. The proposed organisational design, which includes the VIO and area managers, addresses the need for - and interactions between the 5 systems within an organisation. The executive board takes on the system 5 function, with the VIO and area managers representing system 4 and system 3 respectively. This approach facilitates the cycle of corporate strategy development, business as usual and the initiation of management of organisational change.

Although still early days, the implementation of the new organisational design has generally showed a positive impact on the case study organisation, as evidenced by positive reception from the executive board and area managers. The structural change allows the organisation to have a functioning meta-system that adopts a holistic view of the organisation, with the operation being controlled and monitored by the middle-level management (i.e. area managers). Although the results from one case study cannot be generalised to all organisations, the paper provides valuable insight into a KIBS organisation in terms of structural change and value creation that is applicable to many knowledge-based businesses. Of course, while the paper reports the initial implementation and 
impact of this novel organisational design; its long term impact will need to be monitored over time. However, the concept of the VIO, as set out above, can still be further applied to more organisations in the future, to generalise the concept and empirically investigate its impacts more widely.

\section{REFERENCE}

[1] Bettencourt, L., et al., Client Co-production in Knowledge-intensive Business Services. Operations management: a strategic approach, 2005: p. 273.

[2] Løwendahl, B., Strategic management of professional service firms. 2005: Copenhagen Business School Press DK.

[3] Butler, H.N. and B.H. Kobayashi, Unlocking the law: Building on the work of Larry E. Ribstein. International Review of Law and Economics, 2014. 38, Supplement(0): p. 2-4.

[4] Henderson, W.D., From Big Law to Lean Law. International Review of Law and Economics, 2014. 38, Supplement(0): p. 5-16.

[5] Ribstein, L.E. The Death of Big Law. 2010; Available from: http://works.bepress.com/ribstein/22.

[6] Susskind, R.E., Tomorrow's lawyers: An introduction to your future. 2013: Oxford University Press Oxford.

[7] Barton, B.H., A glass half full look at the changes in the American legal market. International Review of Law and Economics, 2014. 38, Supplement(0): p. 29-42.

[8] Pleasence, P., N.J. Balmer, and R. Moorhead, A Time of Change: Solicitors' Firms in England and Wales. Available at SSRN 2202126, 2013.

[9] RBS, A perspective on the legal market. 2014, The Royal Bank of Scotland: UK.

[10] Johansson, M. and A. Jonsson, The package logic: A study on value creation and knowledge flows. European Management Journal, 2012. 30(6): p. 535-551.

[11] Vargo, S.L. and R.F. Lusch, Evolving to a New Dominant Logic for Marketing. Journal of Marketing, 2004. 68(1): p. 1-17.

[12] Prahalad, C.K. and V. Ramaswamy, Co-opting customer competence. Harvard business review, 2000. 78(1): p. 79-90.

[13] Grönroos, C., Service management and marketing: customer management in service competition. 2007: John Wiley \& Sons.

[14] Beer, S., The heart of enterprise. 1979, Chichester: Wiley.

[15] Porter, M.E., Competitive advantage : creating and sustaining superior performance. 1985, New York: Free Press.

[16] Stabell, C.B. and Ø.D. Fjeldstad, Configuring value for competitive advantage: on chains, shops, and networks. Strategic management journal, 1998. 19(5): p. 413-437.

[17] Lindgreen, A., et al., High-tech, innovative products: identifying and meeting business customers' value needs. Journal of Business \& Industrial Marketing, 2009. 24(3/4): p. 182-197.
[18] Gummesson, E., Toward a theory of professional service marketing. Industrial Marketing Management, 1978. 7(2): p. 89-95.

[19] Pan, Y.-C., P. Jackson, and D. Limburg. Value Creation Logics: A UK Case Study. in 20th UK Academy for Information Systems Conference 2015 (UKAIS 2015). 2015. Oxford, UK.

[20] Stauss, B., F. Nordin, and C. Kowalkowski, Solutions offerings: a critical review and reconceptualisation. Journal of Service Management, 2010. 21(4): p. 441-459.

[21] Liu, A.H., Customer value and switching costs in business services: developing exit barriers through strategic value management. Journal of Business \& Industrial Marketing, 2006. 21(1): p. 30-37.

[22] Aarikka-Stenroos, L. and E. Jaakkola, Value co-creation in knowledge intensive business services: A dyadic perspective on the joint problem solving process. Industrial Marketing Management, 2012. 41(1): p. 1526.

[23] Senge, P.M., The fifth discipline : the art and practice of the learning organization. 1st ed. ed. 1990, New York: Doubleday.

[24] Seddon, J., Systems thinking in the public sector : the failure of the reform regime - and the manifesto for a better way. 2008, Axminster: Triarchy.

[25] Beer, S., Brain of the firm: the managerial cybernetics of organization. 1972: London: Allen Lane.

[26] Ashby, W.R., An Introduction to Cybernetics. 1956, London: Chapman \& Hall.

[27] Espejo, R. and A. Gill, The viable system model as a framework for understanding organizations. Phrontis Limited \& SYNCHO Limited, 1997.

[28] Sun, J.-F. and W.-Y. Liu, Design of Equipment Procurement Project Organization Based on Viable Systems Model. Procedia Engineering, 2011. 24(0): p. 809-815.

[29] Preece, G., D. Shaw, and H. Hayashi, Using the Viable System Model (VSM) to structure information processing complexity in disaster response. European Journal of Operational Research, 2013. 224(1): p. 209-218.

[30] Preece, G., P.D. Shaw, and P.H. Hayashi, Application of the viable system model to analyse communications structures: A case study of disaster response in Japan. European Journal of Operational Research, 2014(0).

[31] Yin, R.K., Case Study Research Design and Methods. 2003, Newbury Park, CA: Sage.

[32] Ghauri, P.N. and K. Grønhaug, Research methods in business studies: A practical guide. 2005: Pearson Education. 